\title{
Formation Pressure Evolution in Lynedoch Fields, Northern Bonaparte Basin, Australia
}

\author{
Suliman Ahmed Hamid Fadul ${ }^{1}$, Ye Jia Ren ${ }^{1}$, Cao Qiang ${ }^{1} \&$ Liu Wenchao ${ }^{1}$ \\ ${ }^{1}$ Key Laboratory of Tectonics and Petroleum Resources, China University of Geosciences MOE, Wuhan, China \\ Correspondence: Suliman Ahmed Hamid Fadul, Key Laboratory of Tectonics and Petroleum Resources, China \\ University of Geosciences MOE, Wuhan 430074, China. Tel: 86-132-7792-8597. E-mail: Nokkaa08@gmail.com
}

Received: January 18, 2012 Accepted: January 31, 2012 Online Published: June 19, 2012

doi:10.5539/esr.v1n2p122 URL: http://dx.doi.org/10.5539/esr.v1n2p122

\begin{abstract}
The Lynedoch Fields are located in the flanks of Calder Graben. Wells lynedoch-1, lynedoch-2 and Seismic line N11809 are selected to evaluate the pressure evolution history, investigate the mechanisms of overpressures generation and the timing of oil and gas generation from the potential hydrocarbon source rock. Three areas of pressure evolution were identified namely normal pressure, slight excess pressure and intense excess pressure. The pressure releases are consistent with the tectonic events increasing with depth and dissipating laterally. The peak of excess pressure generation, the peak sedimentation rates in wells Lynedoch-1 and Lynedoch-2 and the peak generation of oil and gas of the same wells were occurred during the Late Cretaceous at 65Ma. High sedimentation rates with rapid subsidence and oil and gas generation are the main favorable conditions for overpressure generation in the study area.
\end{abstract}

Keywords: overpressure mechanisms, high sedimentation rates, generation, expulsion, Lynedoch Fields

\section{Introduction}

Lynedoch Fields comprise two wells Lynedoch-1 and Lynedoch-2 (Figure 1). Lynedoch-1 was drilled in 1973 to test a low relief anticline within the flanks of the Calder Graben and terminated in Jurassic sediments at a total depth of $3967 \mathrm{~m}$. The well Lynedoch-2 was drilled to a total depth of $4225 \mathrm{mDF}$ to test sands of Early to Middle Jurassic of Plover Formation with the Darwin Radiolarite as the secondary objective. Two-dimensional Seismic surveying conducted on the Lynedoch Fields based on the NT96 and NT97 surveys and the data was tied into the key wells in the immediate area. The succession penetrated at Lynedoch-2 was as expected from Lynedoch-1, with the exception of the presence of the Elang Formation and the absence of the Cleia Formation. The Fields offer opportunities for the delineation of structural and stratigraphic traps within the flanks of Malita and Calder Grabens and along their margins. No pressure measurements were conducted in well Lynedoch-1. At the well Lynedoch-2 the measurements of drill stem test (DST) were not run. However, the formation pressure tests and samples were taken in well Lynedoch-2 using RFT pressure measurements. A total 66 pressure readings were attempted and 14 readings were acquired in depth intervals of $3825.5 \mathrm{~m}$ to $3906 \mathrm{~m}$. The maximum pressure value acquired was $51.73181 \mathrm{MPa}$ at depth $3883 \mathrm{~m}$, whereas the minimum pressure value recorded was $40.95 \mathrm{MPa}$ at depth $3826 \mathrm{~m}$. This study aimed to evaluate the pressure evolution history, investigate the mechanisms of overpressures generation and the timing of oil and gas generation from the potential hydrocarbon source rock. 


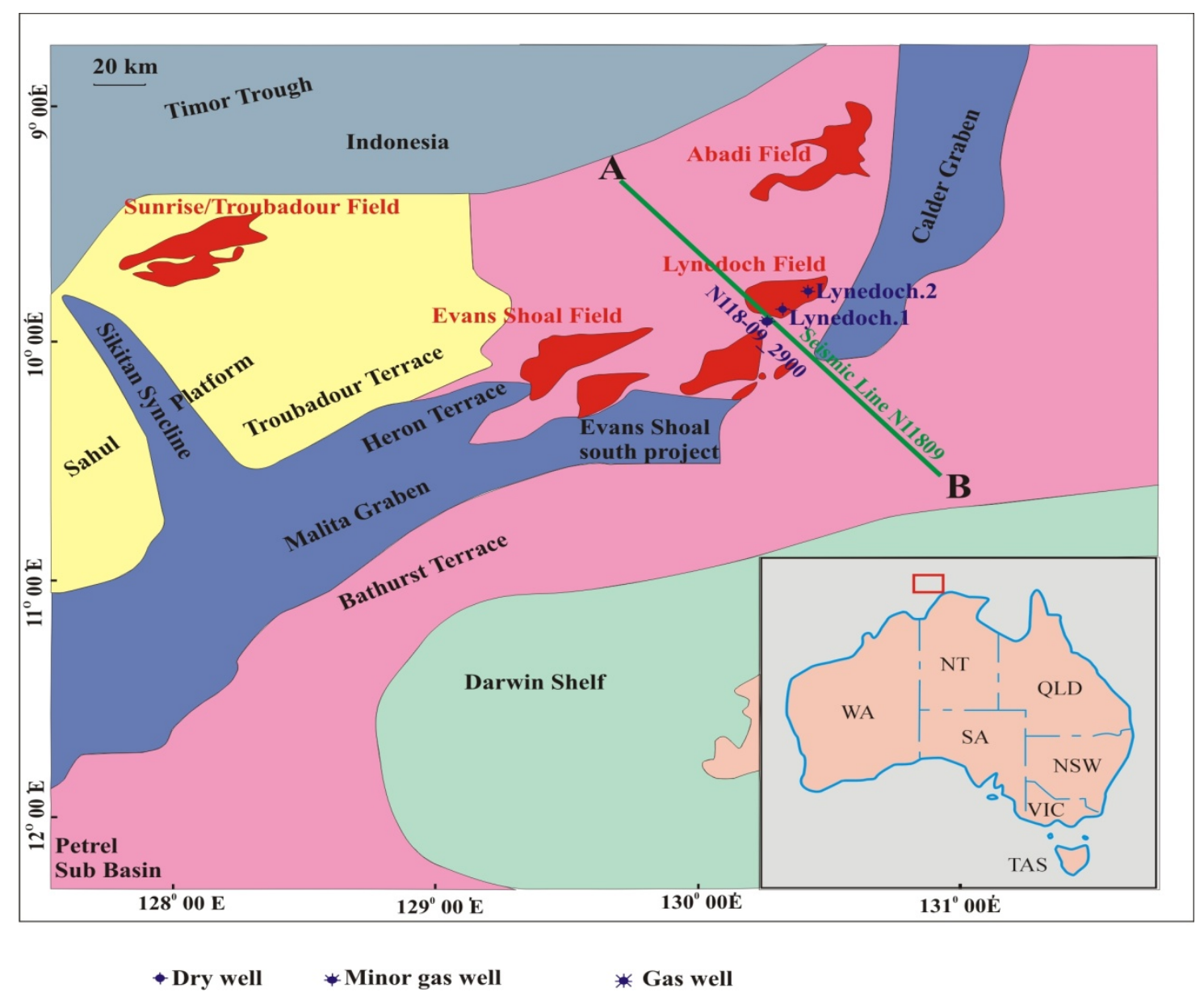

Figure 1. Location map of Lynedoch Fields showing wells Lynedoch-1, Lynedoch-2 and Seismic line N11809 passing over the virtual well N118-09_2900

\section{Geological Settings}

Lynedoch Fields lie within the north eastern portion of the Bonaparte Basin in the southern extent of the Calder Graben. The main tectonic events in the Northern Bonaparte Basin were formed by Mesozoic rifting which started at Late Triassic and continued throughout the Jurassic (Figure 2), which may be related to Gondwanan "break-up" along the northwestern margin of Australia. The northeast-southwest trending faults in the Northern Bonaparte Basin lead to rapid subsidence in the Malita and Calder grabens, which were developed as major Mesozoic depocentres in the basin. The major mappable seismic surfaces associated with "break-up" events are the Callovian Unconformity, intra-Valanginian Unconformity, and Aptian Unconformity. The main reservoirs in the Northern Bonaparte Basin occur in the Middle-Upper Jurassic Plover Formation. The Plover Formation is a regionally widespread predominantly fluvio-deltaic sequence, which grades into a tidal-estuarine/deltaic and marine shore face succession towards the Sunrise-Troubadour area in the northern part of the Sahul Platform. Post-rift subsidence of the Malita Graben resulted in the deposition of the Upper Jurassic to Lower Cretaceous Flamingo Formation, which varies in thickness across the northern Bonaparte Basin, however, the Flamingo Formation is absent in the wells of the Lynedoch Fields and thickens significantly towards the Malita Graben depocentre. The top of the Flamingo Formation occurs at the Intra-Valanginian Unconformity. The Cretaceous Bathurst Island Group, containing glauconitic claystone Formation is overlying the Intra-Valanginian Unconformity. The Aptian Unconformity marks the top of the Echuca Shoals which is characterized by a condensed radiolarian claystone /calcilutite section. The post-Albian sequence comprises a succession of marine shelf/slope sediments, which is dominated by carbonate deposits throughout the Paleocene to recent time (Figure 2). 


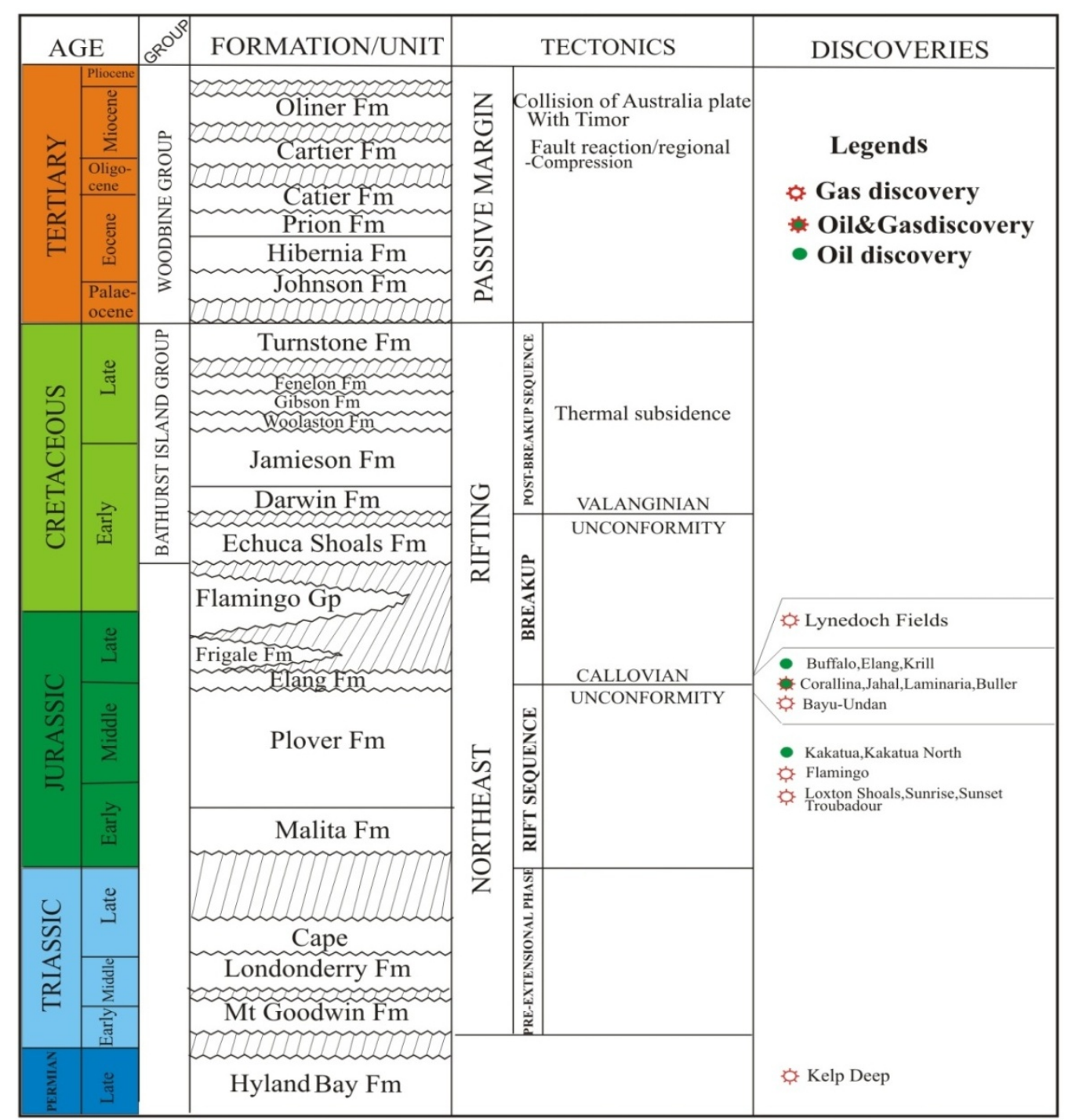

Figure 2. Stratigraphy, tectonics, and petroleum discoveries of Northern Bonaparte Basin, Australia

\section{Materials and Methods}

\subsection{Methods}

\subsubsection{One-dimensional BasinMod}

One-dimensional modeling of a single well location utilizing BasinMod 1D technique that uses mathematical method to reconstruct the burial history, thermal history and generation history determining the subsidence and sedimentation rates, excess pressure, and the maturation parameters, such as the time of onset, peak and end of oil generation according to the equations of backstripping and tectonic subsidence (Steckler \& Watts, 1978) as follows:

$$
\begin{gathered}
D t=\left[S \frac{(\rho m-\rho s)}{(\rho m-\rho w)}-\Delta S L \frac{\rho w}{(\rho m-\rho w)}\right]+\left(W_{d}-\Delta S L\right) \\
\rho s=\frac{\sum_{i}\left[\Phi_{i} \rho w+\left(1-\Phi_{i}\right) \rho_{s g i}\right] S_{i}}{S}
\end{gathered}
$$


Where:

$\mathrm{Dt}=$ the amount of tectonic subsidence (water column (m) in past time).

$\mathrm{S}=$ the total stratigraphic thickness of the sediment column corrected for compaction (m).

$\rho_{\mathrm{s}}=$ the average density of the sediment stratigraphic column $\left(\mathrm{g} / \mathrm{cm}^{3}\right)$.

$\mathrm{W}_{\mathrm{d}}=$ the palaeo-water depth $(\mathrm{m})$.

$\Delta \mathrm{SL}=$ the relative increment for eustatic sea-level variation $(\mathrm{m})$.

$\rho_{\mathrm{m}}=$ the density of asthenosphere $\left(\mathrm{g} / \mathrm{cm}^{3}\right)$.

$\rho_{\mathrm{w}}=$ the density of water $\left(\mathrm{g} / \mathrm{cm}^{3}\right)$.

$\Phi_{\mathrm{i}}=$ the porosity of stratigraphic unit I (dimensionless).

$\rho_{\mathrm{sgi}}=$ the grain density of stratigraphic unit $\mathrm{i}\left(\mathrm{g} / \mathrm{cm}^{3}\right)$.

$\mathrm{S}_{\mathrm{i}}=$ the thickness of stratigraphic unit $\mathrm{i}$ after compaction correction.

One dimensional BasinMod comprise the following models below:

1) Krevelen diagram (1961) after Peters et al. (2005):

Characterization of kerogen by van krevelen diagram (1961) after Peters et al., (2005), utilizing the generative amounts of $\mathrm{HC}$ and $\mathrm{CO}_{2}$ in Rock-Eval Parameters $\mathrm{HI}$ (hydrogen index) and OI (oxygen index), and vitrinite reflectance Ro to describe the OM types.

2) Coupled fluid flow Model:

Coupled fluid flow calculation which based on the conservation law, which requires conservation of the mass in the fluid flow model (Huyakorn and Pinder, 1983; Aziz and Settari, 1979) is used as follows:

$$
\frac{\partial}{\partial \mathbf{z}}(\rho \phi)+\mathrm{q}+\nabla \rho v=0
$$

Where: $\rho$ is the density, $v$ is the velocity, $\phi$ is the porosity and $q$ is the source term. Fluid flow calculation requires modeling of fluid transport in the sediments.

3) Darcy velocity:

Darcy velocity is calculated using the Darcy's Law for modeling the movement of liquids using the equation of (Freeze \& Cherry, 1979):

$$
v=\frac{-k \rho g}{\mu} \frac{\mathrm{dh}}{\mathrm{dl}}
$$

Where: $v, k, \rho, g, \mu$ and $\mathrm{dh} / \mathrm{d} 1$ are represented by the Darcy velocity, permeability, density, gravitational acceleration, viscosity and hydraulic gradient, respectively.

4) The equation of the state by Bethke (1985):

The equation of the state suggested by Bethke (1985) for the fluid flow fragments calculation is used to calculate the pressure and temperature relationship of the model as follows:

$$
\rho=\rho_{\mathrm{sc}} \exp [(\mathrm{P}-0.1)-\alpha(\mathrm{T}-25)] \mathrm{kg} / \mathrm{m}^{3}
$$

Where: $\rho$ is the density; $\rho_{\mathrm{sc}}$ is the density at standard surface conditions, $\mathrm{P}$ the pressure in MPa, T the temperature in ${ }^{\circ} \mathrm{C}$, $\alpha$ is estimated as $5 * 10^{-4} \mathrm{C}^{-1}$ and $\beta$ is predicted as $3.4 * 10^{-4} \mathrm{MPa}^{-1}$.

5) The viscosity as a function of temperature:

The viscosity as a function of temperature can be expressed as (Lide, 1997) in the following equation:

$$
\begin{aligned}
& \mu=10^{\mathrm{n}} \\
& \mathrm{n}=\left(\frac{1.3272(10-\mathrm{T})-0.001053(\mathrm{~T}-20)^{2}}{\mathrm{~T}+105}\right)
\end{aligned}
$$


Where $\mu$ is described as the viscosity which varies with temperature and $\mathrm{T}$ is the temperature in ${ }^{\circ} \mathrm{C}$. The equations (5) and (6) are essential for modeling fluid flow in conjunction with pressure and temperature of sediments which are in close relation with density and viscosity.

6) The sediment compaction model:

The sediment compaction is modeled as a function of fluid pressure by the following formula:

$$
\phi=\mathrm{f}(\mathrm{P}), \phi=\frac{\mathrm{e}}{1+\mathrm{e}}, \mathrm{e}=\mathrm{e}_{\mathrm{A}}^{*}\left(\frac{\mathrm{P}_{\mathrm{f}}}{\mathrm{P}_{\mathrm{f}}^{*}}\right)^{\mathrm{A}}(\text { fraction } \mathrm{A})+\left[\mathrm{e}_{\mathrm{B}}^{*}-\mathrm{B}\left(\mathrm{P}_{\mathrm{f}}-\mathrm{P}_{\mathrm{f}^{*}}\right)\right](\text { fraction } \mathrm{B})
$$

Where $\mathrm{e}$ is the void ratio which is $\phi /(1-\phi), \mathrm{e}_{\mathrm{A}}^{*}$ is the initial void ratio of fraction $\mathrm{A}, \mathrm{e}_{\mathrm{B}}^{*}$ is initial void ratio of fraction $\mathrm{B}, \mathrm{P}_{\mathrm{f}}$ are the Frame, or matrix, pressure, $\mathrm{P}_{\mathrm{f}^{*}}$ is the initial frame, or matrix pressure, $\mathrm{A}$ is the exponential compaction factor, $\mathrm{B}$ is the linear compaction factor, fraction $\mathrm{A}$ is the portion of lithology which compacts exponentially (all lithologies except sand), fraction B is the portion of lithology, which compacts linearly (sands) $=1$-fraction A.

7) The fluid pressure algorithm of (Maubeuge \& Lerche, 1993):

The fluid pressure algorithm of (Maubeuge \& Lerche, 1993) which is responsible of handling the excess pressure calculation at each time step in comparison with calculated pressure for the next step is calculated using the following formula:

$$
\mathrm{P}_{\mathrm{x}}=\mathrm{P}_{\text {overburden }}-\left(\mathrm{P}_{\text {hydrostatic }}-\mathrm{P}_{\text {frame }}\right)
$$

8) Transient heat flow Model:

The transient heat flow equation of 1D BasinMod is used to describe the thermal conduction and convection of the heat flow, assuming that the heat transfer in $1 \mathrm{D}$ is by vertical conduction and depends on Fourier's law of heat conduction coupled with the law of conservation which comprises a full differential equation and handles the thermal conductivity and heat capacities of different rock units while the instantaneous variations in the heat flow values are smoothed out over geologic time as a function of thermal conductivity and heat capacity, rather than resulting in sudden changes in the thermal profile as follows:

$$
\mathrm{C}_{\mathrm{v}} \frac{\partial \mathrm{T}}{\partial \mathrm{t}}-\frac{\partial}{\partial \mathrm{x}}\left(\lambda \frac{\partial \mathrm{T}}{\partial \mathrm{x}}\right)-\mathrm{Q}=0
$$

Where: where $C_{v}$ is the volume heat capacity in $J / m^{3} K, \mathrm{~T}$ is the temperature in Kelvin, $\lambda$ is the thermal conductivity, $\mathrm{t}$ is the time and $\mathrm{Q}$ is the heat source term. Transient heat flow model could only be used with the fluid flow algorithm rather than mechanical compaction methods due to the necessity of calculating fluid flow dependent parameters.

9) The exponential equation (after Sclater \& Christie, 1980):

The exponential equation (after Sclater \& Christie, 1980) is used for porosity calculation:

$$
\mathrm{P}=\mathrm{P}_{0} \exp ^{(-\mathrm{kz})}
$$

Where: $\mathrm{P}$ is porosity (\%), Po is initial porosity (\%), $\mathrm{k}$ is compaction factor adjusted for varying compressibilities of different lithologies $\left(\mathrm{m}^{-1}\right)$ and $\mathrm{z}=$ depth $(\mathrm{m})$.

10) Modified Kozeny-Carman equation is used to calculate permeability in 1D model:

$$
\mathrm{K}= \begin{cases}\frac{0.2 \Phi^{3}}{S^{2} o(1-\Phi)^{2}} & (\Phi \geq 0.1) \\ \frac{20 \Phi^{5}}{S^{2} o(1-\Phi)^{2}} & (\Phi<0.1)\end{cases}
$$


Where: $\mathrm{K}=$ permeability $(\mathrm{md}), \Phi=$ porosity (dimensionless), $\mathrm{S}_{\mathrm{O}}=$ specific surface area of the rock $\left(\mathrm{m}^{2}\right)$.

11) Maturation and hydrocarbon generation and expulsion model:

Predicted maturation and timing of hydrocarbon generation and expulsion are based on Lawrence Livermore National Laboratory (LLNL) vitrinite and kerogen kinetics.

\subsubsection{Two-dimensional BasinMod}

Two-dimensional BasinMod software package is used to reconstruct the maturation and generation histories, while the fluid flow Model of Bredehoeft et al.1994, Lee \& Williams (2000) which was modified from the equation of Bethke (1989) in which the oil and gas generation are included as fluid source Terms ( $\mathrm{q}_{\mathrm{kerogen}-\mathrm{oil}}$ and $\mathrm{q}_{\text {oil-gas }}$ ) is used for fluid flow and overpressure calculations as follows:

$$
\begin{gathered}
\varphi \beta \frac{\mathrm{P}}{\partial \mathrm{t}}=\frac{\partial}{\partial \mathrm{x}}\left[\frac{\mathrm{K}_{\mathrm{x}}}{\mu}\left(\frac{\partial \mathrm{P}}{\partial \mathrm{x}}\right)\right]+\frac{\partial}{\partial \mathrm{z}}\left[\frac{\mathrm{K}_{\mathrm{z}}}{\mu}\left(\frac{\partial \mathrm{P}}{\partial \mathrm{z}}-\rho \mathrm{g}\right)\right]-\frac{1}{1-\varphi} \frac{\partial \varphi}{\partial \mathrm{t}}+\varphi \alpha \frac{\partial \mathrm{T}}{\partial \mathrm{t}}+\left(\mathrm{q}_{\text {kerogen-oil }}+\mathrm{q}_{\text {kerogen-gas }}\right) \\
\alpha=\frac{1}{\rho} \frac{\partial \rho}{\partial \mathrm{T}} \text { and } \beta=\frac{1}{\rho} \frac{\partial \rho}{\partial \mathrm{P}}
\end{gathered}
$$

Where: subscript $\mathrm{x}$ refers to $\mathrm{x}$-direction, and subscript $\mathrm{z}$ refers to $\mathrm{z}$-direction; $\varphi$ is porosity, $\mathrm{P}$ is the pore fluid pressure, $T$ is temperature , $t$ is time, $K$ is permeability, $\rho$ is density, $\mu$ is viscosity, $\alpha$ is fluid thermal expansibility, $\beta$ is fluid compressibility and Q is pressure source. The equation (12) can be used to calculate the net pressure change resulting from various hydrologic and geological processes and the flow from the source beds acts to dissipate the pressure build-up in rocks, therefore the net pressure depends on rate of compaction (sedimentation), rate of hydrocarbon generation, the permeability of the reservoir and confining rocks and the rate of aquathermal expansion.

\subsection{Materials and Input Parameters}

The precision of basin modeling is greatly influenced by the effectiveness and accuracy of various inputs parameters. Data from boreholes, seismic surveys, well tests and geochemical analyses have been used in this study. The major input parameters comprise the stratigraphic thicknesses, burial depths, absolute ages of stratigraphic units that were interpreted from the regional stratigraphy using Geological Time Scale of (Haq et al., 1987) as a guide for generalized ages of stratigraphic units and ages of regional unconformities throughout the study area, whereas the ages at the system and series boundaries were adjusted to the (Harland, 1989) Geologic Time Scale. lithology of each stratigraphic unit, and the eroded thicknesses in the subsurface during the main uplift events, organic thermal indicators, include vitrinite reflectance values, heat flow values, the extrapolated bottom whole temperatures and the surface temperature, porosities, permeabilities, Rock-Eval pyrolysis parameters, RFT pore fluid pressure measurements from the well of the Lynedoch-2. Seismic line N11809 of the study area is also utilized to predict the pressure evolution which comprises eight key stratigraphic horizons as shown in (Figure 3). The initial porosity, matrix density, matrix thermal conductivity and matrix heat capacity, the densities and composition for water, crude oil and natural gas at the subsurface and the salinity of groundwater are adopted from the default values in BasinMod Software package. 


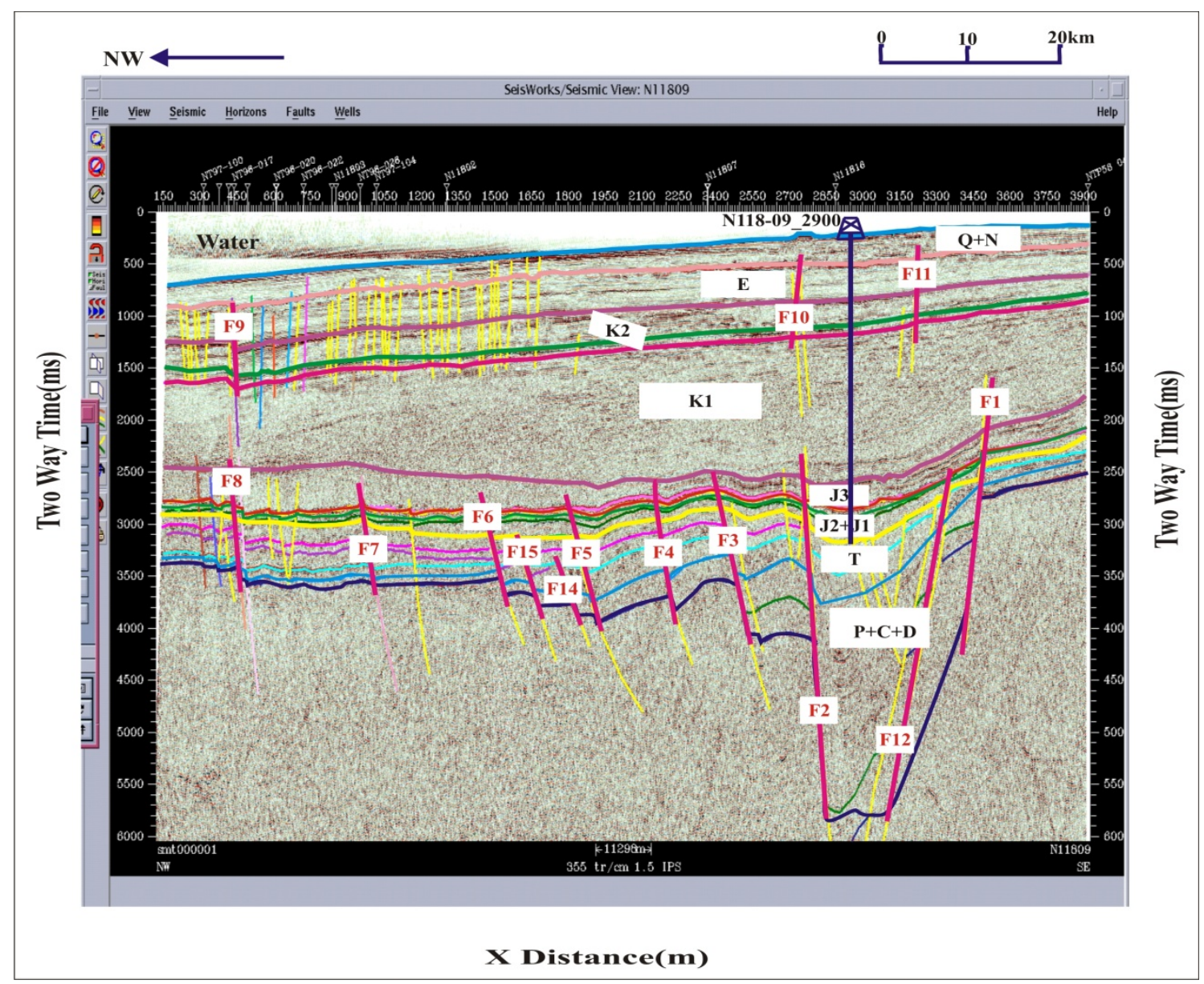

Figure 3. Two-Dimensional Seismic Section N11809 of Bathurst Terrace and passing through Calder Graben and Lynedoch Fields depicting the key Stratigraphic horizons denoted in black capital alphabets as follows: G+N

$=$ Oliver, Barracouta and Alaria formations, $\mathrm{E}=$ Cartier Formation, $\mathrm{K} 2=$ Turnstone and Hibernia formations, $\mathrm{K} 1=$ Darwin, Jamieson, Wangalu and Vee formations, J3 = Elang, Flamingo and Echuca Shoals formations, $\mathrm{J} 2+\mathrm{J} 1=$ Plover Formation, $\mathrm{T}=$ Malita Formation and $\mathrm{P}+\mathrm{C}+\mathrm{D}=$ Pollard, Mt Goodwin and Hayland Bay formations, while the faults are segregated by red color of the letter $\mathrm{F}$ ( $\mathrm{F} 1$ to F15)

\section{Results}

BasinMod one-dimensional that utilizes mathematical technique is used to analyze different geological scenarios for pressure evolution in Lynedoch Fields. The Seismic line N11809 that passes through the virtual well N118-09_2900 (Figure 3) was also used to predict the two-dimensional pressure evolutions in these Fields. The emphasis was to determine the pressure evolution and identify the causes of overpressure.

\subsection{Pressure Evolution in the Lynedoch Fields}

BasinMod 1D software is used to recover the formation pressures of single wells of Lynedoch-2 in Lynedoch Fields. Overpressure can, in principal, only be, calibrated if the water flow and water balance is adjusted correctly throughout the entire basin, therefore in overpressure modeling, the permeabilities of many layers, lithologies and rock types must be adjusted simultaneously. On average, the water flow is upward and therefore calibration should usually be performed from the top to down and from more to less permeable lithologies. The fluid pressures have been compiled from RFT performed in the well Lynedoch-2 and 14 pressure measurements were recorded. The results have shown that the onset of excess pressure was occurred at Early Cretaceous while the peak was occurred during the Late Cretaceous (Figure 4B). The maximum pressure value of $51.731 \mathrm{MPa}$ was measured at Echuca Shoals Formation. The plotted pressure data against the depth in the Echuca Shoals Formation has resulted in identification of depth intervals that are likely to contain overpressure (Figure 4A). 

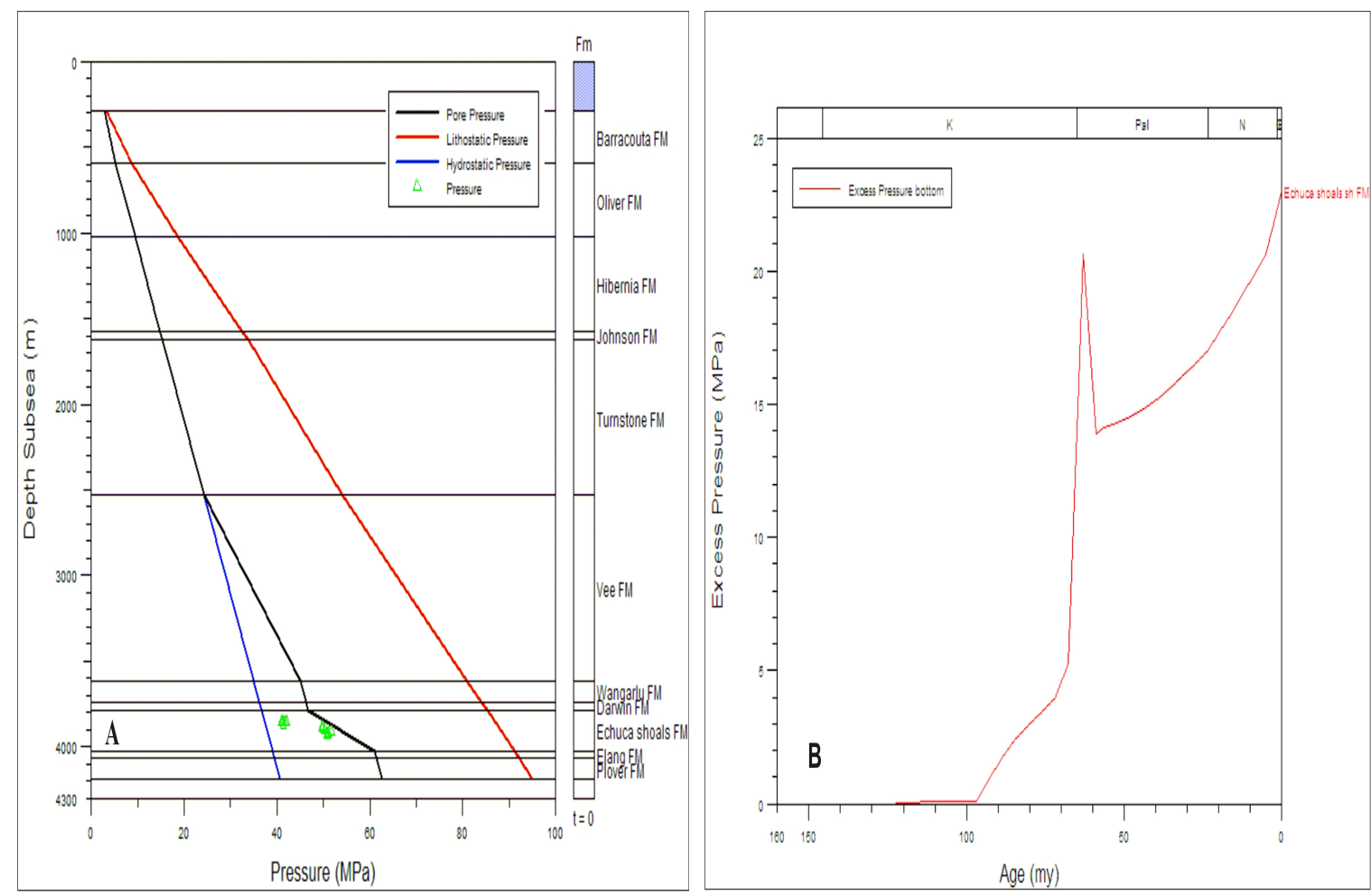

Figure 4. Schametic diagrams showing observed pressure data plots of well Lynedoch-2, (A) pressure profile (pressure versus depth), (B) excess pressure curve depicting its peak at (65Ma) Late Cretaceous, also indicated on the plot are reference lines of hydrostatic pressure, pore pressure and lithostatic pressure

The fluid pressure is also modeled based on eight key stratigraphic units of the seismic line N11809 (Figure 5). The modeling comprises the periods of depositional time from Late Carboniferous to the present-day under the assumptions that the bottom boundary is closed to fluid flow and subject to heat flow of $64 \mathrm{mWm}^{2}$ based on the average geothermal gradient of the basin $\left(3.62^{\circ} \mathrm{C} / 100 \mathrm{~m}\right)$, the upper boundary is open to fluid flow and has a fixed temperature of $20^{\circ} \mathrm{C}$ while the lateral boundaries are constants and are assumed to have zero heatflux taking into account the effects of disequilibrium compaction and oil and gas generation on overpressure development and the effects of relative permeability decrease on fluid overpressure have not taken into account in the calculations of the excess pressure. Based on the results of pressure evolution (Figure 5) the excess pressure generation can be interpreted as follows: the intensities of the excess pressure of the Fields is increased with depth, while its magnitudes decrease towards the margin of the Fields until the normal pressures are met. At $91 \mathrm{Ma}$ the excess pressure evolution was occurred at the $\mathrm{J} 2+\mathrm{J} 1$ and increased with depth and reached the maximum value of $30 \mathrm{MPa}$ at the Base of $\mathrm{P}+\mathrm{C}+\mathrm{D}$ and decreased laterally showing little continuity towards the margins until normal pressures are met at the faults F6 and F1 (Figure 5A). At 65Ma the evolution of excess pressure was occurred at the base of $\mathrm{K} 1$ and increased with depth and reached the base of $\mathrm{P}+\mathrm{C}+\mathrm{D}$ with maximum value of $37.5 \mathrm{MPa}$, whereas it decreased laterally and exceeded beyond the fault F8 in NW direction and separated from the normal pressure by fault F1 in SE direction of the Fields (Figure 5 B). At 59Ma the evolution of excess pressure was occurred in the base of $\mathrm{K} 1$ and increased with depth and reached the base of the $\mathrm{P}+\mathrm{C}+\mathrm{D}$ with maximum of value of $40 \mathrm{MPa}$ whereas it decreased laterally towards the margins (Figure $5 \mathrm{C}$ ). At 0Ma (present-day) the evolution of excess pressure occurred at the middle of the K1 and increased with depth and reached the base of $\mathrm{P}+\mathrm{C}+\mathrm{D}$ with maximum value of $51.7 \mathrm{MPa}$, whereas it decreased laterally but it is in greater amount than that of all above mentioned periods and has passed beyond the fault F8 in NW direction of the Fields as well as it exceeds the fault F1 in the SE direction of the Fields (Figure 5 D). The pressure evolution profiles (Figure 5) can be categorized based on their intensities into normal pressures, slight excess pressures and intensive excess pressures and they are reliable pressure profiles. 

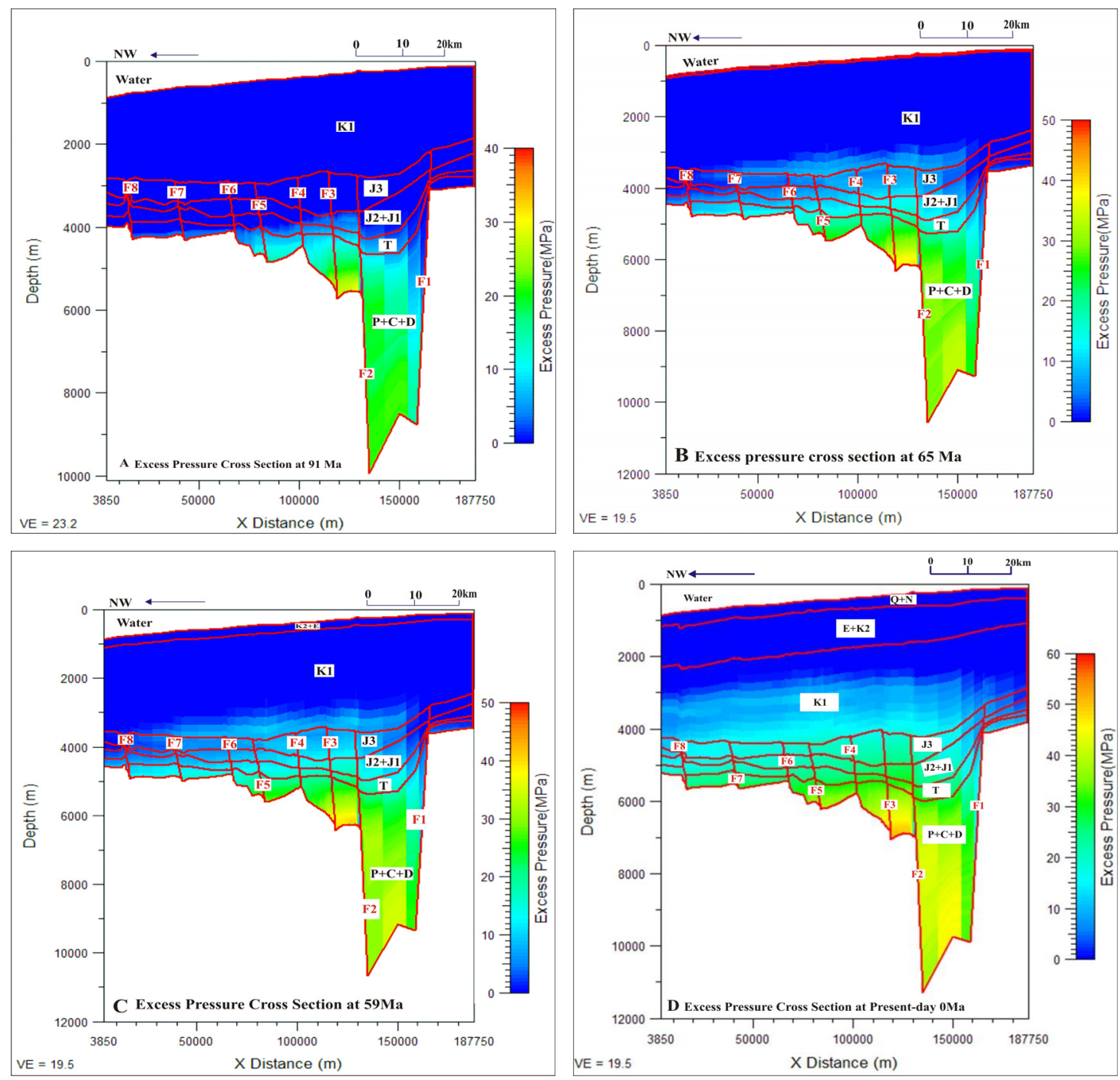

Figure 5. Schematic diagrams showing Excess Pressure evolution of Lynedoch Fields and the surrounding area along Seismic Line N11809. (A) At 91 Ma. (B) At 65Ma. (C) At 59 Ma. (D) At 0Ma. G+N = Oliver, Barracouta and Alaria formations, $\mathrm{E}=$ Cartier Formation, $\mathrm{K} 2=$ Turnstone and Hibernia formations, $\mathrm{K} 1=$ Darwin, Jamieson, Wangalu and Vee formations, J3 = Elang, Flamingo and Echuca Shoals formations, J2 $+\mathrm{J} 1=$ Plover Formation, $\mathrm{T}$

$=$ Malita Formation and $\mathrm{P}+\mathrm{C}+\mathrm{D}=$ Pollard, Mt Goodwin and Hayland Bay formations, while the faults are segregated by red color of the letter F (F1 to F8)

\subsection{Mechanisms of Overpressure Evolution}

Overpressure typically is defined as pore fluid pressure that significantly exceeds hydrostatic pressure of a column of water or formation brine (Dickinson, 1953). Overpressure, the difference between the pore pressure and hydrostatic and it directly controls fluid flow. Another way to view overpressure, in terms of the dynamics of subsurface fluid flow is the inability of formation fluids to escape at a rate which allows equilibration with hydrostatic pressure, the hydrostatic pressure gradient of $0.433 \mathrm{psi} / \mathrm{ft}$ serves as a reference of pressure-depth ratios, greater than $0.433 \mathrm{psi} / \mathrm{ft}$ represents overpressure conditions. The overpressure generation and expulsion during the evolution of the sedimentary basin have a close relationship with the large scale hydrocarbon generation and migration, the direction and concentration of which are controlled mainly by the formation pressure distribution (Ye et al., 2003; Vannucchi, 2001; Schegg et al., 1999). The analysis of models of overpressure suggests that three main mechanisms can result in the development of overpressure these are: sedimentation, hydrocarbon generation and vertical migration of fluids through faults. In this paper we concentrate on the effects of sedimentation and hydrocarbon generation on overpressure development in Lynedoch Fields. 


\subsubsection{Sedimentation and Porosity Reduction}

The main factor which determines changes of pore space is compaction or decomposition of rocks under changing load. Sediment compaction is mostly a mechanical process resulting in the reduction of porosity by increases in vertical stress due to the loading on the sedimentary pile. Lateral deformation is commonly ignored. The temporal evolution of fluid pressure as a result of mechanical compaction is controlled by the relationship between sediment permeability and sedimentation rates. Sedimentation rates provide the time of the most pronounced periods of overpressure build-up due to the sediment loading. BasinMod1D and 2D are used to depict the mechanism of the overpressure generation and evolution in Lynedoch Fields through reconstruction of sedimentation rates and tectonic subsidence evolution of the wells Lynedoch-1 (Figure 6A) and Lynedoch-2 (Figure 6B) and compared with the results of 2D pressure evolution of the seismic line N11809 (Figure 5). Sedimentation and tectonic subsidence analysis (Figure 6) has shown three low periods of sedimentation and tectonic subsidence rates with one high period (peak sedimentation) at the Late Cretaceous (65Ma) in both wells. The sedimentation rates during the Late Cretaceous are $290 \mathrm{~m} / \mathrm{Ma}$ and $688.25 \mathrm{~m} / \mathrm{Ma}$ while the tectonic subsidence rates are $74.79(\mathrm{~m} / \mathrm{Ma})$ and $92.20(\mathrm{~m} / \mathrm{Ma})$ in wells Lynedoch-1 and Lynedoch-2 respectively.

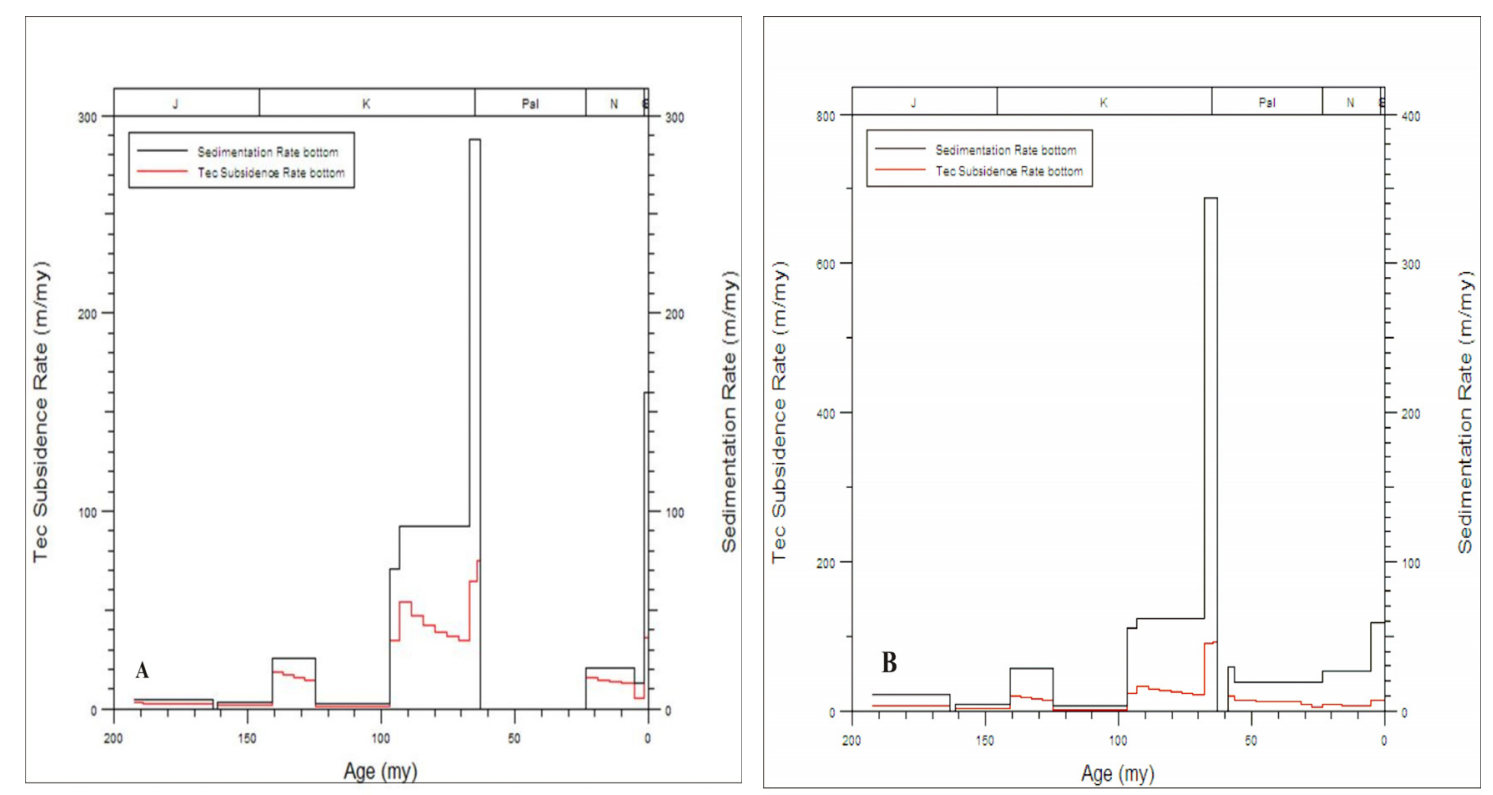

Figure 6. Schematic diagrams of sedimentation and tectonic subsidence rates in Lynedoch Fields, (A) well Lynedoch-1, (B) well Lynedoch-2

\subsubsection{Hydrocarbon Generation}

The generation of hydrocarbons involves the transformation of kerogen in organic matter into liquid and gaseous phase. It results in an increase of the fluid volume and a very small decrease in the volume of organic matter. The decrease of volume of the solid phase is insignificant. The increase of the fluid volume leads to the growth of formation pressure and related reduction of the effective stress. The wells Lynedoch-1and Lynedoch-2 and Seismic survey line N11809 were modeled to reconstruct burial, thermal and hydrocarbon generation histories of the Fields to assess the relationship between the excess pressures yielded in the Fields and the hydrocarbon generation from the source rock. The source rock and their present day maturities are identified using 1D and 2D BasinMod software. The present day thermal regime is obtained by calculating the heat flow in the wells Lynedoch-1 $\left(53.4 \mathrm{mWm}^{2}\right)$, Lynedoch-2 $\left(68.3 \mathrm{mWm}^{2}\right)$ and the Seismic Line N11809 $\left(64 \mathrm{mWm}^{2}\right)$. The source rock of Plover Formation in Lynedoch Fields was deposited during the Middle Jurassic and the TOC is variable from well to another (Table 1). In well Lynedoch-1 4 TOC readings were recorded with the average of $1.225 \mathrm{wt} \%$. In well Lynedoch-2 4 readings of the TOC were recorded in the Plover Formation source rock with the average of 0.995; while the average TOC of the Plover Formation source rock from the horizons of Seismic Line N11809 is $2.20 \mathrm{wt} \%$. 
Table 1. Abundance of organic matter of the Lynedoch Fields, wells Lynedoch-1 and Lynedoch-2

\begin{tabular}{lccccccc}
\hline Well name & $\begin{array}{c}\text { Depth } \\
(\mathrm{m})\end{array}$ & Formation & Lithology & $\begin{array}{c}\mathrm{TOC} \\
(\mathrm{wt} \%)\end{array}$ & $\mathrm{HI}_{(\mathrm{mgHC} / \mathrm{gTOC})}$ & $\mathrm{Ol}_{\text {(mgCO2/gTOC) }}$ & $\left(\mathrm{S}_{1}+\mathrm{S}\right)(\mathrm{mg} / \mathrm{g})$ \\
\hline Lynedoch-1 & 3911 & Plover & Claystone & 1.61 & 93.79 & 6.2 & 2.22 \\
Lynedoch-1 & 3931.92 & Plover & Claystone & 0.69 & 37.68 & 73.91 & 0.41 \\
Lynedoch-1 & 3950 & Plover & Claystone & 1.78 & 91.57 & 15.73 & 2.43 \\
Lynedoch-1 & 3962.4 & Plover & Claystone & 0.82 & 40.24 & 92.68 & 0.49 \\
Lynedoch-2 & 4050 & Plover & Claystone & 0.63 & 71.43 & 23.81 & 0.77 \\
Lynedoch-2 & 4060 & Plover & Claystone & 0.88 & 59.09 & 6.82 & 0.91 \\
Lynedoch-2 & 4130 & Plover & Claystone & 1.0 & 61 & 23 & 0.72 \\
Lynedoch-2 & 4135 & Plover & Claystone & 1.31 & 49.62 & 19.85 & 0.82 \\
\hline
\end{tabular}

TOC is total organic matter content (wt. \%). (S1+S2) are the total amount of petroleum that might be generated from a rock. S1 is free hydrocarbons $(\mathrm{mg} / \mathrm{g})$. S2 is the hydrocarbon generation potential of the source rock $(\mathrm{mg} / \mathrm{g})$

Analysis of organic matter suggests that the Plover Formation source rock in Lynedoch Fields is a gas-prone source rock with OM type П\&Ш kerogens dominantly (Figure 7). The generation of hydrocarbons from the wells of the Lynedoch Fields is demonstrated using 1-D BasinMod software through reconstruction of the burial, thermal, generation histories of Lynedoch-1 and Ly nedoch-2 (Figure 8). In well Lynedoch-1 the Plover Formation source rock entered oil widow at late Cretaceous and wet gas window at Early Neogene (Figure 8A), and the peak generation was recognized during late Cretaceous to early Paleogene (Figure 10). In well Lynedoch-2 the Plover Formation source rock also entered oil widow at late Cretaceous and wet gas window at Early Neogene (Figure 8B), and the peak generation was recognized during late Cretaceous to early Paleogene (Figure 11). The source rock maturation levels and hydrocarbon generation across the Lynedoch Fields were also conducted using Seismic Survey Line N11809 that passes through the Fields on the virtual well N118-09_2900.The maturity (Figure 9) is interpreted to have been initiated at a level of thermal maturity of $0.5 \%-0.7 \%$ Ro and concluded at a level of thermal maturity of $1.3 \%-2.0 \%$ Ro. The generation evolution history along this line can be described as follows: At $91 \mathrm{Ma}$ the Plover Formation source rock entered mid-mature oil window at the center of Calder graben and early-mature oil window at the margins of Calder graben (Figure 9A). At $65 \mathrm{Ma}$ the Plover Formation entered mid-mature oil window at the margins of Calder graben and late-mature oil window at the center of Calder graben (Figure 9B). At 35.4Ma the Plover Formation entered mid-mature oil window at the margins of Calder graben and late-mature oil window at the center of Calder graben (Figure 9C). At the present-day (0Ma) the Plover Formation source rock entered late-mature oil window at the margins as well as the center of the Calder graben (Figure 9D). The modeling results are calibrated to the measured vitrinite reflectance values for the wells of the Lynedoch Fields and to the Seismic Line N11809. The correspondence between the simulated and the measured values is remarkably good, which indicates that the accuracy is relatively higher for both $1 \mathrm{D}$ and $2 \mathrm{D}$ modeling. 


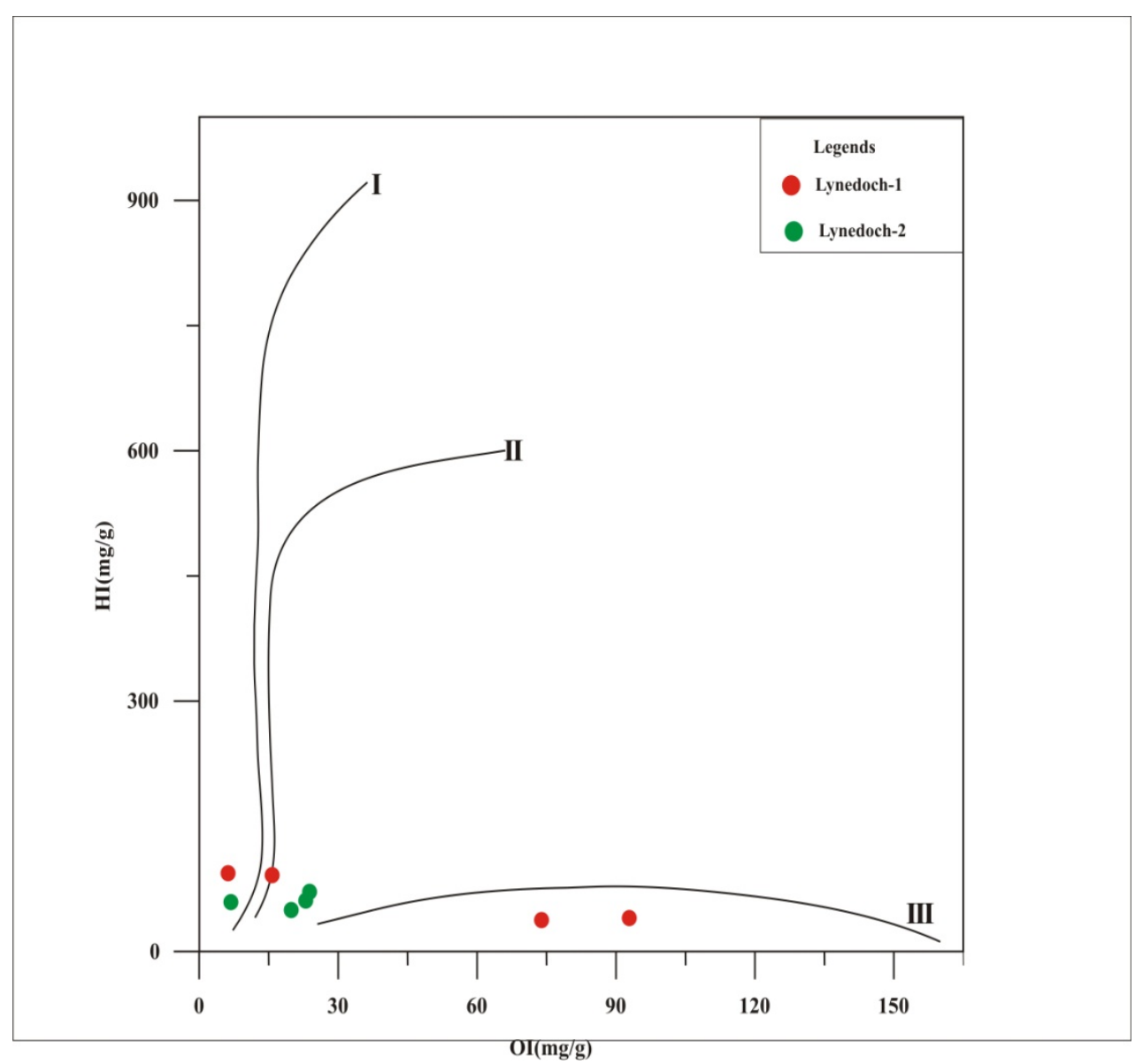

Figure 7. Organic Matter types of Plover Formation source rock in Lynedoch Fields
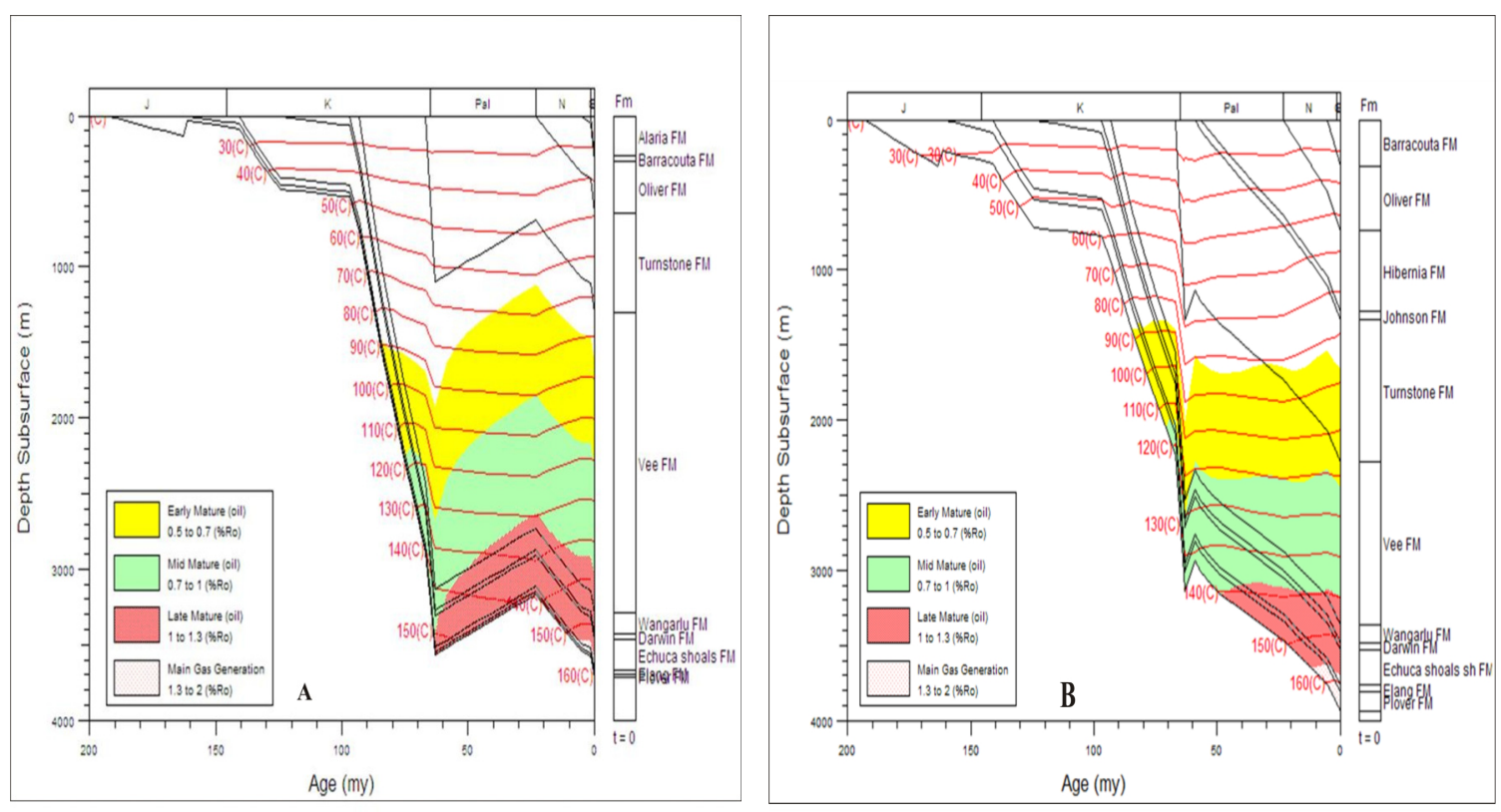

Figure 8. The burial history and isotherms of the wells of Lynedoch Fields, (A) The well Lynedoch-1, (B) The well Lynedoch-2 

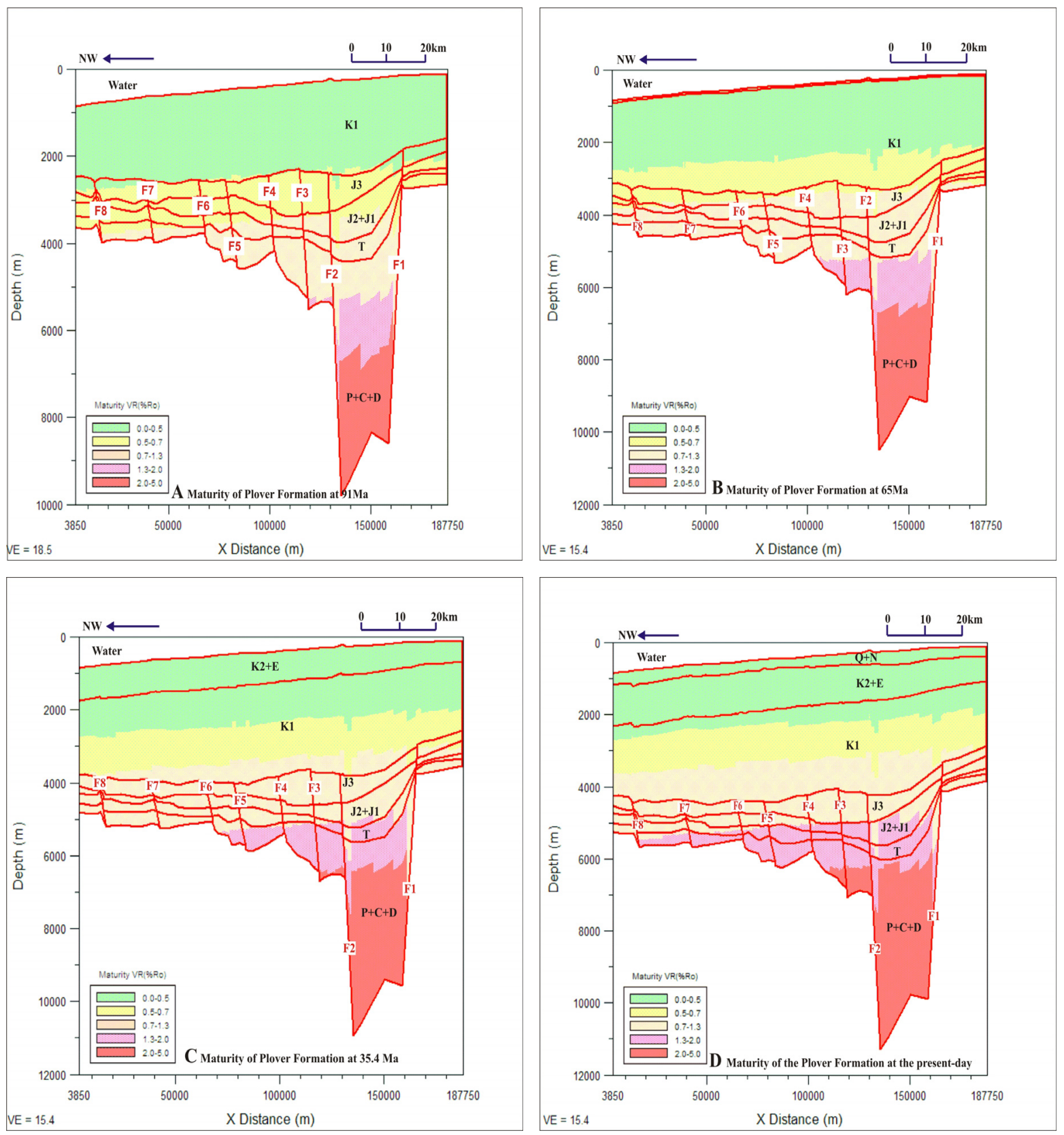

Figure 9. Schematic diagrams showing maturation evolution histories of the Plover Formation source rock along Seismic Line N11809. (A) 91 Ma. (B) 65Ma. (C) 35.4 Ma. (D) Present-day 0Ma. G+N = Oliver, Barracouta and Alaria formations, $\mathrm{E}=$ Cartier Formation, $\mathrm{K} 2$ = Turnstone and Hibernia formations, K1= Darwin, Jamieson, Wangalu and Vee formations, $\mathrm{J} 3=$ Elang, Flamingo and Echuca Shoals formations, J2+J1=Plover Formation, $\mathrm{T}$

$=$ Malita Formation and $\mathrm{P}+\mathrm{C}+\mathrm{D}=$ Pollard, Mt Goodwin and Hayland Bay formations, while the faults are segregated by red color of the letter F (F1 to F8) 

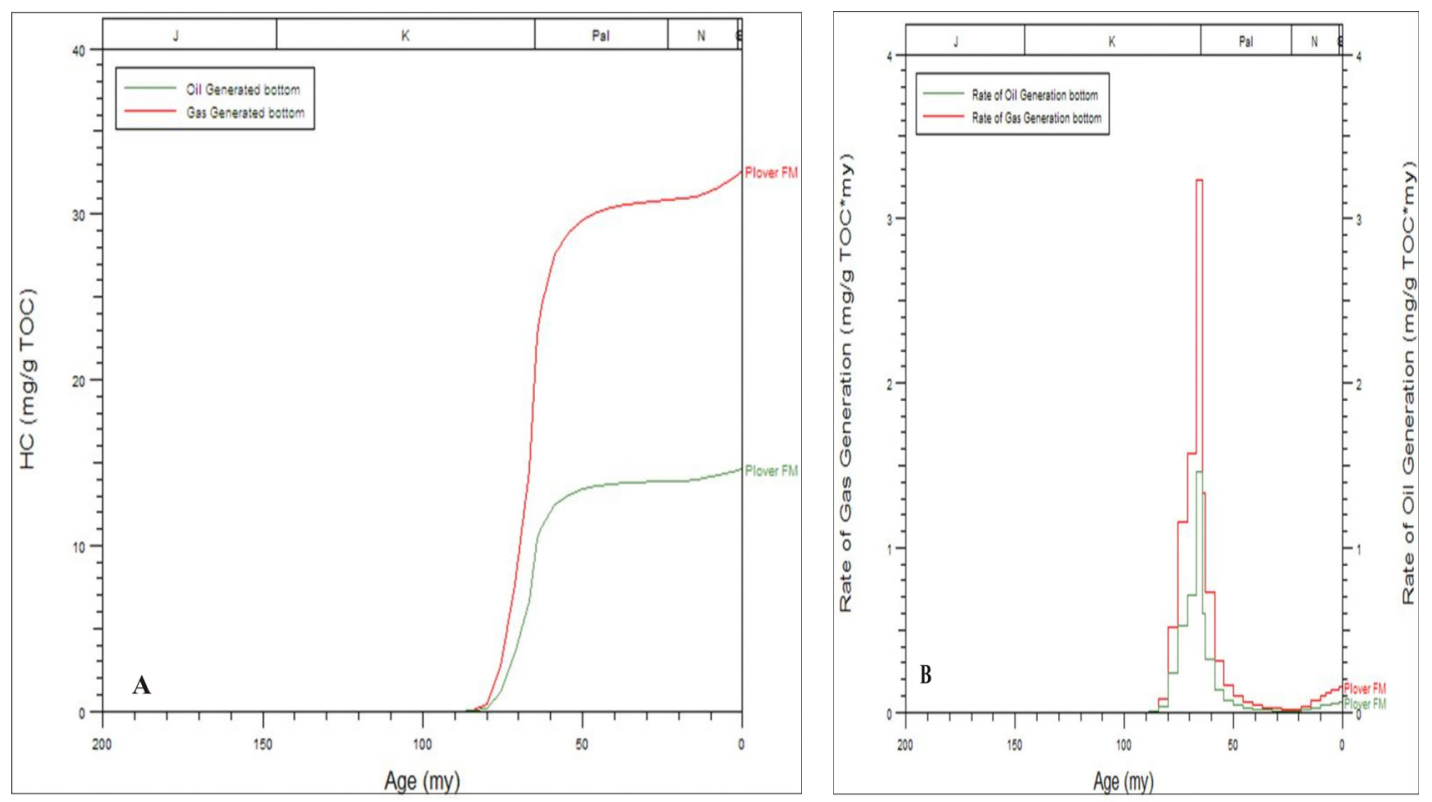

Figure 10. Generation of hydrocarbon history in well lynedoch-1, (A) hydrocarbon generating intensity, (B) the rate of generation $(\mathrm{mg} / \mathrm{g}$ TOC.Ma)
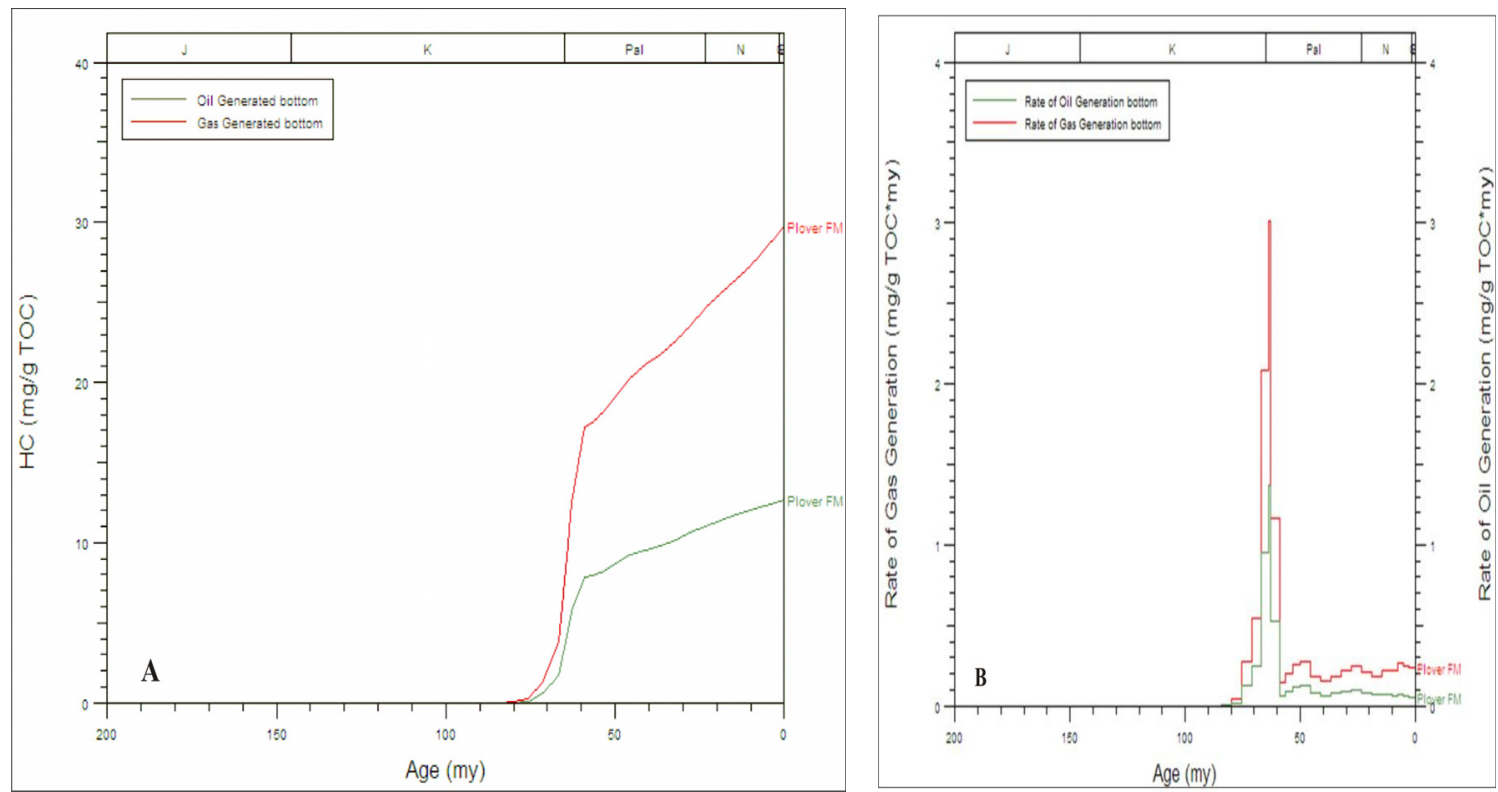

Figure 11. Generation of hydrocarbon history in well lynedoch-2, (A) hydrocarbon generating intensity, (B) the rate of generation $(\mathrm{mg} / \mathrm{g}$ TOC.Ma)

\section{Conclusions}

The formation pressure evolution in Lynedoch Fields is modeled using wells Lynedoch-1 and Lynedoch-2 and Seismic line N11809. The resulted pressure profiles composed of normal pressures, slight excess pressures and intense excess pressures increasing with depth. The magnitude of the excess pressure decreases and dissipates laterally until it meets the normal pressures due to the faults activities (seismic line N11809). The pressure releases are consistent with the tectonic events of the study area and reached its peak during the Late Cretaceous (65Ma). The peak sedimentation and tectonic subsidence rates within the wells of the Lynedoch Fields were also occurred during the Late Cretaceous at $65 \mathrm{Ma}$. The peak sedimentation and tectonic subsidence rates are in coincidence with the peak oil and gas generation and also with peak of the excess pressure generation from the 
same wells. Source rocks of Plover Formation in Lynedoch Fields entered oil window with OM types II\&III dominantly and it is in wet-gas window at the present-day. The mechanisms that lead to generation of high excess pressures in the Felds are: 1) high sedimentation rates with rapid subsidence that accompanied low permeability sediments resulted in disequilibrium of the sediment compaction; 2) The hydrocarbon generation that resulted from the process of kerogen transformation into liquid hydrocarbons and cracking into gas. The correspondence between simulated and measured values of both pressure and maturity are significantly good and accurate for both $1 \mathrm{D}$ and 2D modeling.

\section{Acknowledgements}

We would like to acknowledge that the financial support provided by China University of Geosciences (Wuhan).

\section{References}

Burrus, J. (1998). Overpressure models for clastic rocks, their relation to hydrocarbon expulsion: a critical reevaluation, in Law, B. E., Ulmishek, G. F., \& V. I. Slavin (ed.). Abnormal pressures in hydrocarbon Environments. AAPG Memoir, 70, 35-63.

Cadman, S. J., \& Temple, P. R. (2003). Bonaparte Basin, NT, WA, AC \& JPDA, Australia Petroleum Accumulations Report 5 ( $2^{\text {nd }}$ ed.). Canberra: Geoscience Australia.

Cao Qiang, Ye Jiaren, Wang Wei, Shi Wan Zhong, \& Chen Chun Feng. (2009). Preliminary Prediction and Evaluation on Source Rock in Low Exploration Basin: A Case Study from the Northeast Depression, South Yellow Sea Basin, East China. Journal of Earth Science, 20(5), 836-847. http://dx.doi.org/10.1007/s12583-009-0070-8

David S. Gordon, \& Peter B. Flemings. (1998). Generation of overpressure and compaction-driven fluid flow in a Plio-Pleistocene growth-faulted basin, Eugene Island 330, offshore Louisiana. Basin Research, 10, 177-196. http://dx.doi.org/10.1046/j.1365-2117.1998.00052.x

Gluyas, J., \& Swarbrick, R. (2004). Petroleum Geoscience. (2 ${ }^{\text {nd }}$ ed.). Oxford, UK: Blackwell Science Ltd.

J, M. Verweij, H, J. Simmelink, R. T. Van Balen, \& P. David. (2003). History of petroleum systems in the southern part of the Broad Fourteens Basin. Netherlands Journal of Geosciences / Geologie en Mijnbouw, $82(1), 71-90$.

Ozkan Huvaza, Hasan Sarikayab, \& Taner Isik. (2007). Petroleum systems and hydrocarbon potential analysis of the northwestern Uralsk basin, NW Kazakhstan, by utilizing 3D basin modeling methods. Marine and Petroleum Geology, 24, 247-275. http://dx.doi.org/10.1016/j.marpetgeo.2006.11.002

Salvin, V. I., \& E. M. Smirnova. (1998). Abnormally high formation pressures: origin, prediction, hydrocarbon field development, and ecological problems, in Law, B. E., Ulmeshek, G. F., \& V. I. Salvin (ed.). Abnormal pressures in hydrocarbon environments. AAPG Memoir, 70, 105-114.

Sheng He, \& Mike Middleton. (2002). Heat flow and Thermal maturity modeling in the Northern Carnarvon Basin, North West Shelf, Australia. Marine and Petroleum Geology, 19, 1073-1088. http://dx.doi.org/10.1016/S0264-8172(03)00003-5

Suliman Ahmed Hamid Fadul, Ye Jia Ren, Cao Qiang, \& Zhang Yang. (2011). Petroleum System of Evans Shoal Gas Field, northern Bonaparte Basin, Australia. Journal of American Science, 7(10), 36-48.

Swarbrick, R. E., \& M. J. Osborne. (1998). Mechanisms that generate abnormal pressures: an overview in Law, B. E., Ulmishek, G. F., \& V. I. Slavin (ends.) Abnormal pressures in hydrocarbon Environments. AAPG Memoir, 70, 13-34.

Thomas, H. A., \& Kauerauf, I. (2009). Fundamentals of Basin and Petroleum Systems Modeling (2 ${ }^{\text {nd }}$ printing). Berlin: Springer.

Tissot, B. P., \& Welte, D. W. (1978). Petroleum Formation and Occurrence (2 ${ }^{\text {nd }}$ ed.). Berlin: Springer. http://dx.doi.org/10.1007/978-3-642-96446-6

Ye Jiaren, Hairuo Qing, Stephen, L. Bend, \& Huirong, Gu. (2007). Petroleum systems in the offshore Hihu Basin on the continental shelf of the East China Sea. AAPG Bulletin, 91(8), 1167-1188. http://dx.doi.org/10.1306/02220705158 